\title{
Implementation of the chemicals regulation REACH - Exploring the impact on occupational health and safety management among Swedish downstream users
}

\author{
Linda Schenk ${ }^{\mathrm{a}, \mathrm{b}, *}$, Ann-Beth Antonsson ${ }^{\mathrm{c}, \mathrm{d}}$ \\ ${ }^{a}$ Department of Philosophy and History, KTH-Royal Institute of Technology, Brinellvägen 32, 10044 Stockholm, Sweden \\ ${ }^{\mathrm{b}}$ Unit of Work Environment Toxicology, Institute of Environmental Medicine, Karolinska Institute, 17177 Stockholm, Sweden \\ c IVL - Swedish Environment Research Institute, Box 210 60, SE-100 31 Stockholm, Sweden \\ ${ }^{\mathrm{d}}$ Department of Health Systems Engineering, KTH-Royal Institute of Technology, Alfred Nobels Alle 8, SE-141 52 Huddinge, Sweden
}

\section{A R T I C L E I N F O}

Article history:

Received 11 April 2015

Received in revised form 17 July 2015

Accepted 1 August 2015

\section{Keywords:}

REACH

Occupational health and safety

Policy implementation

Safety data sheets

Exposure scenario

\begin{abstract}
A B S T R A C T
In the present study we have examined how the European chemicals regulation Registration, Evaluation, Authorisation and Restriction of Chemicals (REACH) has influenced occupational risk management of chemicals at Swedish downstream user companies. The data were collected through interviews with occupational health and safety professionals, safety representatives and authority employees. The results show that most of the informants had scarce knowledge about REACH and that REACH implementation has not had any major impacts on downstream users' occupational risk management, but the impacts the regulation has had were perceived as positive. For instance, clear substance identification and increased hazard information were appreciated improvements of safety data sheets (SDS). However, with regards to identifying how to safely use a substance or product neither the SDSs nor the attached exposure scenarios were perceived as sufficient. REACH was not perceived as a major driver for substitution but has had some impact on substitution, either by requiring it for certain substances as through the authorisation procedure or facilitating the identification of relevant substances to substitute as more information on hazards has become available. The obstacles to REACH implementation are similar to those of occupational health and safety legislation; lack of awareness, understanding and/or incentives to take action. Especially smaller companies with their limited resources lag behind. Reaching the full potential of REACH requires more work on motivating and supporting downstream users to fulfil their REACH obligations.
\end{abstract}

(c) 2015 Elsevier Ltd. All rights reserved.

\section{Introduction}

In the present study we have examined the influence of the European chemicals regulation Registration, Evaluation, Authorisation and Restriction of Chemicals substances (REACH) on chemical risk management at Swedish workplaces. This regulation came into force in June 2007, and is being implemented in a stepwise manner until 2018. REACH is aimed to improve the protection of human health and environment from hazardous chemicals as well as to enhance innovation and competitiveness of the EU chemicals industry (EU, 2006). The regulation applies "without prejudice to Community workplace and environment

\footnotetext{
* Corresponding author at: Department of Philosophy and History, KTH-Royal Institute of Technology, Brinellvägen 32, 10044 Stockholm, Sweden.

E-mail addresses: schenk@kth.se (L. Schenk), ann-beth.antonsson@ivl.se (A.-B. Antonsson).
}

legislation" (EU, 2006, preamble), but many of its provisions impact chemicals risk management in the workplace.

Swedish occupational health and safety (OHS) legislation places the main responsibility for preventing ill health and accidents resulting from working conditions on the employer (Swedish Parliament, 1977), through e.g. requirements on performing risk assessments and work systematically with OHS. Similar requirements are found in the EU frame work directive on occupational safety and health (EU, 1989) and its daughter directive the Chemical Agents Directive (EU, 1998). Risk assessment of chemical exposures is today incorporated in the Swedish Work Environment Authority (SWEA) provisions on chemical safety in the work environment (SWEA, 2011a). These provisions also connect to the requirements on systematic work environment management (SWEM) first developed in the 1990s (SWEA, 2001). Amongst other requirements, the SWEM and chemical safety provisions state that the employer is responsible for giving the employees the 
information necessary for preventing ill-health and accidents at work. Safety data sheets (SDS) are important tools for communication of health risks and safety measures along the supply chain as well as within companies. The information in the SDS makes up the basis for workplace risk assessments of hazardous chemicals and SDSs for these chemicals are to be made available to employees (SWEA, 2011a).

SWEA also issues the provisions on occupational exposure limits (OELs, SWEA, 2011b). In Sweden, OELs have been set since the late 1960s and the list is updated with a few years' intervals. Swedish OELs are binding and pragmatic, i.e. they are set taking socioeconomic and technical feasibility into account as well as the scientific evaluation of health effects. The scientific evaluation of health effects is performed by an independent expert group while the extrapolation from data to OEL and corresponding consequence analyses are performed by desk officers at SWEA.

Enforcement of Swedish OHS legislation is performed by a division of SWEA, which is also responsible for enforcement of several REACH obligations connected to work environment (REACH articles: $14.6,34 \mathrm{~b}, 35,37.4,37.5,38,60.9,60.10,67.1$; as listed in $\S 17$ of the Swedish work environment ordinance). In general terms SWEA's REACH enforcement aims to ensure that manufacturers and users apply the OHS risk management measures (RMMs) resulting from REACH procedures and that downstream users, when required, provide information to the European Chemicals Agency (ECHA) and/or their supplier. Other REACH obligations are enforced mainly by the Swedish Chemicals Agency which is the Swedish competent authority for REACH. ECHA has no enforcement responsibilities but acts as a central point in the $\mathrm{REACH}$ system as it manages the IT-infrastructure and co-ordinates member states' competent authorities.

\subsection{Obligations and tasks under REACH}

REACH replaces a large number of different EU (nonoccupational) chemical regulations. A major change to these old regulations is that $\mathrm{REACH}$ places greater responsibility on manufacturers, importers and downstream users to ensure that they manufacture, place on the market or use substances in such a way that they do not adversely affect human health. There are several different procedures under REACH. Registration is the procedure under which manufacturers and importers need to register a substance if they manufacture or import more than 1 tonne per year. With increasing tonnage the information required about the substances' properties and safe uses increases. Evaluation designates the procedure under which ECHA controls the completeness of registration dossiers but also substance evaluation, under which competent authorities in the member states may perform in depth evaluations assessing the need for additional regulatory action. Authorisation is the procedure under which certain substances of very high concern, listed in Annex XIV of REACH, are banned for any use unless an authorisation is granted by the European Commission. Restriction is the procedure under which specific uses of certain substances are prohibited; restrictions are listed in Annex XVII of REACH.

Industry's responsibility to produce information about risks and safe uses is thus introduced with the registration procedure. For most substances that were already manufactured or placed on the market before REACH's entry into force registration is being implemented stepwise. Registration deadlines have been set according to tonnage imported or manufactured per registrant and year as well as hazardous properties. The first REACH registration deadline was on November 30th 2010 (>1000 tonnes, substances that are carcinogenic, mutagenic or toxic to reproduction substances $>1$ tonne, and substances dangerous to aquatic organisms or the environment $>100$ tonnes), the second May 31st 2013 (100-1000 tonnes) and the third and final deadline will be on May 31st 2018 (1-100 tonnes).

Registrants have to perform a chemical safety assessment for any substance they manufacture or import in amounts greater than 10 tonnes per year. The chemical safety assessment includes hazard assessments and assessments of exposure for all supported uses along the supply chain. A chemical safety assessment may also be performed by downstream users if their uses are not supported by any upstream registrant. The supported uses and required RMMs are to be determined using derived no-effect levels (DNELS) as benchmarks. DNELs are delineated in Annex I of REACH as a value to represent an exposure level below which humans are not expected to experience adverse health effects. In the chemical safety assessment DNELs are to be derived for each relevant exposure route (dermal, oral, inhalation), exposure duration (acute/ short-term and long-term), effect (local and systemic) and population (workers and the general population). The resulting information about supported uses and required RMMs, including any DNELs for the worker population, is to be submitted to ECHA but also communicated down the supply chain with an SDS.

While the registration requirements apply to single substances, requirements on SDSs apply to both substances and mixtures. In the SDS a supplier, be it a registrant or a downstream user, describes the properties of the substance (or mixture), its hazards and instructions for handling, disposal and transport and also first-aid, fire-fighting and exposure control measures. The requirements for the compilation of the SDS are now specified in Article 32 and Annex II of REACH. Mostly these requirements are the same as in previous regulations concerning SDSs (major changes for SDSs for substances have been summarised for instance by ECHA (2014)).

A new concept introduced by REACH is the extended SDS which includes the so called exposure scenarios. Exposure scenarios are attachments to the SDS that provide information on how the exposure of workers, consumers and the environment to a substance can be controlled in order to ensure its safe use. Companies have to compile exposure scenarios for any substance for which they have performed a chemical safety assessment under REACH. Attached exposure scenarios must be consistent with the information in the main body of the SDS. Exposure scenarios may be compiled also for mixtures containing substances that have a chemical safety assessment, but this is not mandatory under REACH. Upon having received an exposure scenario downstream users have to consult it and within 12 months take appropriate action to ensure safe use (REACH Article 37 and 39).

REACH thus entails much work and responsibility for registrants but also for the different kinds of downstream users. Downstream users' tasks and obligations under the different REACH procedures to some degree depend on the kind of downstream use (e.g. formulation, production of articles or end use). Among these tasks and obligations are to:

- Provide information regarding their uses to suppliers of substances, so that registrants may include these uses in their chemical safety assessment.

- Implement measures specified by their supplier to ensure the safe use of the substance.

- In case the downstream user's use is not supported (and will not become by current or other supplier), if exemptions do not apply and if substitution is unfeasible: prepare a downstream user chemical safety report.

- Inform their supplier if they have new information on the hazards of the substance or the risk management advice is not appropriate.

- Comply with any authorisation and/or restriction requirements as well as requirements regarding substances in articles. 
- In case the downstream user is a formulator: provide customers with appropriate information on hazards and conditions of safe use for the mixture.

- In case the downstream user produces articles: comply with requirements on registration and notification of substances in articles (Article 7) and the duty to communicate information on substances in articles (Article 33).

More information about the points in this non-exhaustive list of downstream user roles or obligations can be found in REACH Articles 7, 31, 33, 34, 37-39.

\subsection{REACH impact on occupational risk management of chemicals}

REACH is a comprehensive regulation and many of its obligations connect to the protection of the worker population. A short comparison of Swedish OHS legislations and REACH obligations connected to registration that affect OHS management is presented in Table 1. Several impact assessments prior to the adoption of $\mathrm{REACH}$ expected the regulation to result in large benefits for the worker population (RPA, 2003; Pickvance et al., 2005). Some of the benefits that are expected for occupational risk management are outlined in Table 2. REACH prompts the production of initial

\section{Table 1}

Brief overview of overlaps and differences between the REACH obligations stemming from the registration procedure and Swedish OHS legislation.

\begin{tabular}{|c|c|c|}
\hline & REACH registration & OHS legislation \\
\hline \multirow[t]{2}{*}{ Coverage } & $\begin{array}{l}\text { Substance specific - } \\
\text { combined exposures not } \\
\text { covered (n.b. SDSs for } \\
\text { products should cover the } \\
\text { mixture of that product. } \\
\text { Exposure scenarios are only } \\
\text { required for single } \\
\text { substances.) }\end{array}$ & $\begin{array}{l}\text { Workplace specific - } \\
\text { including combined } \\
\text { exposures }\end{array}$ \\
\hline & $\begin{array}{l}\text { Substances that are } \\
\text { produced or imported to EU, } \\
\text { low tonnages are generally } \\
\text { exempted as are certain } \\
\text { groups of substances or } \\
\text { mixtures }\end{array}$ & $\begin{array}{l}\text { All substances at the } \\
\text { workplace }\end{array}$ \\
\hline $\begin{array}{l}\text { Information } \\
\text { flow along } \\
\text { the supply } \\
\text { chain }\end{array}$ & (extended) SDS & (extended) SDS \\
\hline \multirow[t]{3}{*}{ Design of RMM } & $\begin{array}{l}\text { General RMMs aimed at all } \\
\text { workplaces along the supply } \\
\text { chain }\end{array}$ & Workplace specific RMMs \\
\hline & $\begin{array}{l}\text { Designed by the } \\
\text { manufacturer/importer }\end{array}$ & $\begin{array}{l}\text { Designed by the employer } \\
\text { at the workplace }\end{array}$ \\
\hline & $\begin{array}{l}\text { Adherence to occupational } \\
\text { hygiene principles not } \\
\text { required }\end{array}$ & $\begin{array}{l}\text { Occupational hygiene } \\
\text { principles apply: hierarchy } \\
\text { for RMMs }\end{array}$ \\
\hline $\begin{array}{l}\text { Exposure } \\
\text { benchmarks }\end{array}$ & Derived no-effect level & $\begin{array}{l}\text { Occupational exposure } \\
\text { limit }\end{array}$ \\
\hline Standard-setter & Registrants & SWEA \\
\hline $\begin{array}{l}\text { Toxicological } \\
\text { basis }\end{array}$ & Registrants & Independent expert group \\
\hline $\begin{array}{l}\text { Operationalised } \\
\text { by }\end{array}$ & Registrants & Employer \\
\hline $\begin{array}{l}\text { Principle for } \\
\text { selection of } \\
\text { effect }\end{array}$ & $\begin{array}{l}\text { Leading effect - leading to } \\
\text { the lowest derived no-effect } \\
\text { level }\end{array}$ & $\begin{array}{l}\text { Critical effect - effect seen } \\
\text { at the lowest exposures in } \\
\text { data }\end{array}$ \\
\hline $\begin{array}{l}\text { Principle for } \\
\text { extrapolation }\end{array}$ & $\begin{array}{l}\text { Systematic use of } \\
\text { assessment factors, default } \\
\text { factors are described in } \\
\text { REACH guidance (ECHA, } \\
2012 \text { ) }\end{array}$ & $\begin{array}{l}\text { Assessment factors not } \\
\text { used, extrapolation takes } \\
\text { socioeconomic and } \\
\text { technical factors into } \\
\text { account }\end{array}$ \\
\hline
\end{tabular}

Abbreviations: OHS - Occupational Health and safety, RMM - Risk management measure, SDS - safety data sheet, SWEA - Swedish Work Environment Authority.
Table 2

Brief overview of how certain benefits for occupational health and safety management may derive from obligations and procedures under the REACH regulation.

\begin{tabular}{|c|c|}
\hline Possible OHS benefit & REACH obligations and procedures \\
\hline $\begin{array}{l}\text { Increased knowledge about } \\
\text { hazardous properties of } \\
\text { substances }\end{array}$ & $\begin{array}{l}\text { - Registration procedure requires regis- } \\
\text { trants to ensure basic data availability. } \\
\text { Amount according to tonnage starting } \\
\text { at } 1 \text { tonne } \\
\text { - Information on hazardous properties } \\
\text { is to be communicated downstream } \\
\text { with the SDS }\end{array}$ \\
\hline $\begin{array}{l}\text { Increased communication up } \\
\text { and down the supply chain }\end{array}$ & $\begin{array}{l}\text { - Compilation of CSA requires knowl- } \\
\text { edge of downstream uses } \\
\text { - Downstream users are obligated to } \\
\text { communicate upstream if they have } \\
\text { new information on hazards or unsuit- } \\
\text { ability of RMMs }\end{array}$ \\
\hline Promoted substitution & $\begin{array}{l}\text { - Increased data on hazardous proper- } \\
\text { ties due to registration (see also } \\
\text { above) } \\
\text { - Use of substances on the authorisation } \\
\text { list only allowed if authorisation is } \\
\text { granted } \\
\text { - Candidate list substances may, due to } \\
\text { being considered for the authorisation } \\
\text { list, be substituted as an anticipatory } \\
\text { measure } \\
\text { - Restrictions prohibit certain (or all) } \\
\text { uses }\end{array}$ \\
\hline $\begin{array}{l}\text { Improved knowledge about how } \\
\text { to use substances safely }\end{array}$ & $\begin{array}{l}\text { - SA includes risk assessments of known } \\
\text { uses } \\
\text { - CSA may identify uses advised against } \\
\text { - which are then communicated } \\
\text { downstream with the SDS } \\
\text { - Exposure scenarios are required for } \\
\text { substances that have a CSA. Specifies } \\
\text { operational conditions and RMMs } \\
\text { required for safe use, attached to SDS } \\
\text { - Restrictions may be proposed for uses } \\
\text { of substance that pose unacceptable } \\
\text { risk }\end{array}$ \\
\hline $\begin{array}{l}\text { Increased availability of } \\
\text { exposure benchmarks }\end{array}$ & $\begin{array}{l}\text { - CSA and proposals for authorisation } \\
\text { and restriction includes derivation of } \\
\text { DNELs. Mainly due to registration the } \\
\text { number of DNELs derived under } \\
\text { REACH will by far exceed the number } \\
\text { of OELs }\end{array}$ \\
\hline
\end{tabular}

Abbreviations: CSA - chemical safety assessment, DNEL - derived no effect level, OEL - occupational exposure limit, OHS - occupational health and safety, RMM risk management measure.

information on a large number of substances, sets up risk assessment procedures and increases the output of toxicological evaluations of substances. In addition, communication between producers and users about chemical uses and risks should increase. As a result, better information on exposures should become available for risk assessment, improving the RMMs communicated back to users with the SDSs (Musu, 2010, 2004; Walters, 2008). Hammerschmidt and Marx (2014) sketched an occupational health and safety 'ideal REACH world' and identified obstacles to achieving these ideal outcomes. While some obstacles are likely to be permanent, for instance competing objectives of REACH duty holders and legal provisions limiting the scope of REACH, others may be resolved with increased experience, such as the current use of instruments (e.g. exposure modeling tools) which still are under development.

In 2012 the Commission reviewed the implementation of $\mathrm{REACH}$. The review concluded that REACH is functioning well so far, but that there are areas in need of additional improvement. A major issue was the need to improve the quality of the data submitted in the registration process (European Commission, 2013). Nevertheless, it has already been shown that the number of 
substances with classifications has increased (RPA, 2012), but also that substances previously classified have received stricter and/or additional classifications due to REACH obligations (Oltmanns et al., 2014).

In a series of interviews performed during the year before the first registration deadline Cohen (2011) found that representatives from civil society, government and industry all agreed that a successful implementation of REACH would lead to improved protection of human health and the environment. Cohen's informants found registration to be based on a sound principle and that "the market is driving compliance, and downstream users are applying pressure in their suppliers to prepare for and comply with REACH" (p59). However, only one downstream user was represented in the analysed material. Both the authorisation list and the candidate list (which includes candidate substances for possible inclusion in the authorisation list) were perceived as pressures for substitution (compare also to Pelkmans et al., 2013) and while their full potential was unknown industry informants reportedly also perceived the candidate list as a black list.

The increased output of toxicological evaluations has not only affected classification and labelling of substances but also the availability of exposure benchmark values, in the shape of DNELs. According to REACH, DNELs are to be calculated for substances that are produced in quantities above 10 tonnes per year and also for all substances classified as dangerous, persistent, bioaccumulative, toxic substance or very persistent or very bioaccumulative. The number of worker-DNELs is thus expected to rapidly exceed the number of available OELs. After the first registration deadline had passed some 1800 substances had received long-term workerDNELs for the inhalation route (Nies et al., 2013), and currently more than 3000 individual substances (as identified by ECnumbers) have DNELs for workers and long-term inhalation exposure (http://www.dguv.de/ifa/Gefahrstoffdatenbanken/GESTISDNEL-Datenbank/index-2.jsp,2015-03-15). This can be compared with the number of substances on national lists of OELs that cover some 100-800 individual substances depending on country/organisation (Ding et al., 2011).

The relationship between OELs and DNELs has been discussed since before the implementation of REACH started. Previous to the first registration the worker-DNELs were expected to be considerably lower than previously set OELs, mainly due to the different default assessment factors given in the guidance documents (ECHA, 2012; Schenk and Johanson, 2011). However, this expectation has not been realised in the two registration deadlines that have passed to date. Among the DNELs registered so far we find values much higher as well as much lower than corresponding OELs (Nies et al., 2013; Schenk et al., 2015; Tynkkynen et al., 2015). Hammerschmidt and Marx (2014) also showed that a few substances had different DNELs from different registrants; but mostly the differences were within a factor of five. There have been indications since the first registration deadline that the relationship between DNELs and OELs is unclear to EU companies (RPA, 2012).

Shortcomings of the SDS have been found in numerous studies over the years, both in European countries and others; for instance that SDS are not made available to workers, are not fully accurate and/or complete and contain insufficient information to allow identification of all hazards or sufficient RMMs (Nicol et al., 2008; Suleiman and Svendsen, 2014). The SDS improvements required by $\mathrm{REACH}$, both with respect to contents and communication could thus have a major impact on OHS management. Especially the exposure scenarios are of importance, as they are intended to offer more specific information about safe uses of the applicable substances.

Much concern has been directed at occupational health and safety management in micro, small and medium sized enterprises
(SMEs), who have been found to have limited knowledge of relevant regulations and actual hazards of chemical products as well as poorer OHS management (e.g. Walters, 2006; Sørensen et al., 2007; Olsen et al., 2010; Legg et al., 2015). Improved communication along the supply chain, as well as the more detailed information on safe uses in exposure scenarios could be especially beneficial for these smaller companies. However, based on a literature review and interviews with representatives from 12 SMEs in the chemical sector, Pelkmans et al. (2013) found that SMEs doubt the utility of extended SDSs. It was also found likely that awareness of REACH is low among those downstream SMEs that are end users of chemical substances and/or products. A survey of members of a Scandinavian trade association (unnamed but members were expected to be subject to REACH requirements) performed closely before the second registration deadline showed that many SMEs were indeed unaware of REACH. Furthermore, among SMEs aware of REACH more than half believed the regulation did not apply to their operations and even if aware of having obligations under $\mathrm{REACH}$, a majority stated to not understand or only partially understand their REACH obligations (Scruggs et al., 2015). It seems implementation of REACH, like OHS legislation, may be difficult to attain in SMEs due to low awareness of regulatory requirements.

Article 6.2 of the Chemical Agents Directive describes a hierarchy of RMMs ranging from the preferred option of substitution to the last resort measure of personal protective equipment (EU, 1998). In a study on the implementation of the Chemical Agents Directive it was shown that this hierarchy is not adhered to in practice, especially among companies lacking knowledge and economical resources for identifying and implementing RMMs closer to the hazard source (Lißner and Zayzon, 2011). The REACH chemical safety assessment under the registration procedure does not require registrants to consider this hierarchy; hence, it is unclear to what degree exposure scenarios will guide downstream SMEs to a better selection of RMMs.

\subsection{Aims}

Our aim was to study how REACH requirements are implemented in Swedish downstream user companies and how this has affected OHS management. Towards that aim we have investigated whether informants perceived $\mathrm{REACH}$ to have increased the amount and availability of hazard information, if communication up and down the supply chain has been affected and whether REACH implementation has promoted substitution. We have also examined the informants' views in the clarity and sufficiency of SDS and whether these have changed over time. Furthermore, we investigated informants' experience of and opinions on exposure scenarios. A final objective was to probe informants' awareness, understanding and opinion of DNELs, both in relation to building of exposure scenarios as well as in comparison to OELs.

\section{Method}

\subsection{Informants}

Because REACH is a comparably new regulation and indications are that knowledge about it or at least the specific requirements in it are low (e.g. Scruggs et al., 2015) we chose a convenience sample strategy, described in detail in the following sections. We wished to get the perspective from professionals in workplace chemical risk management, employees and authorities. Nineteen informants were recruited, 16 of which had had their profession or commission since before the first registration deadline. Only six of the informants were female, and all employees' representatives were male. 
Occupational hygienists and workplace safety engineers were recruited by the assistance of two Swedish professional organisations, the Swedish Association of Occupational and Environmental Hygiene (SYMF) and the Swedish Association for Occupational Health (FTF). In the case of SYMF a recruitment letter with a link to a short questionnaire and a request to participate in the interview study was sent out to the members by e-mail in June and a reminder in August. In the case of FTF our recruitment letter was posted on the FTF webpage in June, and an e-mail was sent to members in September. The questionnaire was open until midOctober 2014. A similar recruitment strategy has been employed previously with satisfactory response rates (e.g. Schenk and Palmen, 2013). SYMF has about 140 members and FTF about 400, the extent of the overlap in membership between these organisations is unknown. However, in total only twelve individuals responded to the questionnaire (of which three responded after the reminder) and of these seven also agreed to partake in the interview study. Only one of the interviewed identified primarily as a workplace safety engineer, henceforth we will refer to this group of informants as OHS professionals.

We also wished to interview local and regional safety representatives for a view on OHS management from an employee perspective, as this group may have another view on the efficiency and effects of OHS legislation than other groups involved in OHS management (e.g. Frick, 2013; Niskanen et al., 2014). Local safety representatives are active only at their own workplace, while regional safety representatives are a resource for small workplaces (generally less than 50 employees) in their region that do not have a local safety representative. Regional safety representatives thus have experience from many different workplaces that generally are small or even micro sized. The commission as regional safety representative can be full-time or part-time.

Safety representatives were recruited by the help of contacts at the Swedish Trade Union Confederation (LO) and also specifically the trade union IF metall which is the main trade union for manufacturing industry. The two contact persons forwarded our recruitment letter to selected members, some of which forwarded it further. This recruitment letter contained short information about the purpose of the interviews and a request to contact the main author via e-mail if they wanted to receive more information about participation the interview study. One of the authors also recruited informants at a workshop for safety representatives. Four local and four regional safety representatives were interviewed. The interviewed regional safety representatives are active part-time and are also elected as local safety representatives at their own workplace.

One representative for the Swedish Work Environment Authority (SWEA) department for regulations was interviewed, selected because of having been involved in a REACH focused inspection pilot at four companies, 2 registrants and 2 downstream users. Two labour inspectors from SWEA were also interviewed, after being recommended to the authors by a unit head within SWEA's department for regulations. Finally a member from one of the inspection units from Swedish Chemicals Agency was interviewed, selected due to involvement in a pilot project about inspection of exposure scenarios in ten different companies.

\subsection{Data collection and analysis}

All informants were informed about the purpose of the study and methods for data collection before the interviews took place. Each interview started with a swift repetition of this information after which permission to record the interviews and informed consent were collected. Informants were also given the opportunity to ask questions before the interviews started.
The data were collected through semi-structured interviews in Swedish performed in July-December 2014, i.e. more than a year after the second registration deadline. The aim was to cover all key areas and ask key questions in a similar manner, but the order of questions could change between interviews in response to the informants' answers to the previous question. The semi-structured approach also allowed the interviewer to ask for clarification, elaboration or examples. Several issues were in focus throughout the interviews, namely:

- Awareness, use and opinion about OELs.

- Familiarity with REACH, workplace(s)'s relation to REACH.

- Knowledge and opinion about REACH's effects on OHS management.

- Knowledge of and view on communication between suppliers and users.

- Informant's information seeking.

- Use and opinion about SDSs.

- Awareness, use and opinion about extended SDSs and exposure scenarios.

- Awareness, use and opinion about DNELs.

Authority informants were also asked to tell about their experiences from REACH inspection efforts. The prepared questions were mainly open-ended, but in some cases closed questions with follow-up probes were used. For instance with regards to OELs informants were first asked if they had encountered OELs, then probed for information about if and how they use OELs as well as opinions about their function and reliability (in relation to purpose).

The interviews took about an hour each; the shortest interview was $40 \mathrm{~min}$ and the longest $80 \mathrm{~min}$. Most interviews $(n=17)$ were performed over telephone. All interviews were audio recorded and an anonymized summary was written based on the recording after the interview. All informants were given the opportunity to read the summary transcripts and comment on it, which 12 informants did. All interviews were performed and summarized by the first author. Audio files were retained during the analysis phase in order to be able to go back for clarifications. The interview transcripts were thematically analysed and coded, in an iterative process starting using the topics in the interview guide as a starting point but also including inductively induced codes (Patton, 2002). The identified themes are presented and elaborated on in the results section. The findings were discussed and agreed amongst the two authors prior to the submission of any publication.

\section{Results}

Knowledge and experience of the different procedures under REACH varied between informants. All OHS professionals or safety representatives were employed by downstream users according to $\mathrm{REACH}$. The main operations belonged to either production of articles or end-use. In a few cases the company also had partaken in registration and/or preregistration of substances. Consultants and regional safety representatives also worked mostly with downstream users close to the end of the supply chain. Some of the companies used substances falling under the authorisation and/or restriction procedures. However, not all informants were in a position to be aware of all details with regards to such requirements.

In the following sections we start by presenting an outline of the perception of changes in general prompted by REACH. In the next three sections we look closer at SDS, exposure scenarios and DNELs. Each of these sections starts with the perspective from OHS professionals and safety representatives and is closed with a 
paragraph on the authority perspective. The final section presents a brief overview of informants' views on ways forward.

\subsection{REACH brings little new with respect to management of occupational health and safety}

Generally, informants were ambivalent towards REACH as a driving force for improving chemicals risk management in the work environment. Many stated that REACH had had no, or little, impact on work environment so far. However, no or few and mostly manageable draw-backs were identified. The picture of benefits and draw-backs developed during the full interviews.

The benefit of REACH seen by most informants was that of increased or facilitated access to information about chemical risks. This referred both to SDSs and other information pathways such as ECHA's dissemination activities. For instance the ECHA database on registered substances was raised as an appreciated source of information by most OHS professionals. Whether this information access had led to practical RMMs was doubted by or unclear to the informants.

The substance identification improvement was also lifted by a consultant catering some 100 SMEs as a factor facilitating communication with suppliers, as it "has become easier to know what to talk about". However, by the few informants aware of any twoway communication along the supply chain, it was described as something that had been in place since before REACH. There were no indications from our material that communication up the supply chain has increased or broadened in scope due to $\mathrm{REACH}$ obligations.

It was pointed out that companies and trade unions have a long history of efforts towards reducing the number and amount of chemicals used as well as substituting the known hazardous ones. Although opinions differed between informants, most did not find registration a driving force for substitution in their operations. Rather, substitution efforts were reported to have been driven by voluntary measures, trade union pressure and the OHS and environmental legislations in place prior to REACH. Some informants stated that especially carcinogens, mutagens and reproductive toxicants (CMR substances), which are prioritised for substitution under the OHS legislation, have become easier to identify due to the REACH requirements. Despite the emphasis on the importance of previously established driving forces for substitution, it was acknowledged that authorisation will drive substitution for the affected substances. Informants at companies using substances with an upcoming sunset date expressed deep concern about the company's ability to substitute and yet found it unlikely that the affected company would partake in an application for authorisation. The candidate list was mentioned by a few informants, as a list of chemicals that preferably should be avoided. However, it was not described as a black list.

That the authorisation procedure is perceived as stricter than previous regulations promoting substitution was also shown by a concern that this procedure (and in some cases also restriction) will encourage, or perhaps even force, companies to move operations outside EU. For safety representatives this lead to a conflict between different protective aims: protecting workers' health and protecting their employments.

Part of the lack of practical effects of REACH on OHS management seems to lie in the fact that companies find it difficult to identify their REACH obligations. Several OHS professionals expressed uncertainty on whether their companies had REACH obligations and how to comply with these. A theoretical drawback was put forward by one experienced occupational hygiene consultant - that due to the perceived difficulties in complying with REACH new and potentially better RMMs may not be introduced at workplaces. However, the informant had no practical experience of such trade-offs having taken place.

\subsubsection{The authority perspective}

The views presented above resonate well with that of the authority informants. Authority informants agree that REACH is sound in principle but that implementation is incomplete and it is doubtful whether many of the expected positive effects have yet reached the workplace. This was explained partially with companies, both to registrants and different kinds of downstream users, not being fully aware of their REACH obligations. In the case of registrants, authority informants voiced their concern that nonlead members of Substance Information Exchange Forums (SIEF) may lack understanding of their own registration. Furthermore, as downstream users in many cases have not yet, or only recently received exposure scenarios and have a year to implement the described conditions of use, it is still too early for SWEA inspections to be fruitful among downstream users. With respect to authorisation SWEA inspectors had already experienced that this procedure had prompted the phase-out of substances that previous regulations had not targeted. While our collected material did not indicate an increased two-way communication along the supply chain, previous inspection efforts from the Swedish Chemicals Agency have found that registrants have reported to have communicated with downstream users about product uses previous to registration.

\subsection{There is still room for improvements of the safety data sheets}

The SDSs were by most informants perceived as improved, although for varying reasons. OHS professionals appreciated that substance identification has improved in the SDS, which was connected to the facilitation of potential communication with suppliers mentioned in the previous section. Informants among both OHS professionals and safety representatives stated the SDSs had better and more information about hazards. In this respect informants mainly referred to classification, labels and hazard phrases. It was clear that most do not separate between the effects of $\mathrm{REACH}$ and the effects of the regulation on classification, labelling and packaging of substances and mixtures (EU, 2008).

Although finding SDSs improved since REACH entered into force, informants were generally dissatisfied with the SDSs, more specifically with the RMMs prescribed in the SDS. These were mostly described as general, vague and open to interpretation. It was pointed out that the type of routines used for a certain general risk management measure such as glove-use very much affect the protection offered. A repeatedly given example was that the SDS may specify the kind of glove that should be used, but not include any information about how often to change the gloves. Depending on workplace routines for glove change the protection level thus may vary significantly. A difference in opinion on the result of such general measures was seen depending on the position of the informants. Safety representatives tended to find the protective measure insufficient, OHS professionals were more prone to find the protective measure to be excessive or excessive in certain (but every day) situations. Regardless of the standpoint informants referred to the general nature of the protective measures. One regional safety representative, sceptical of the sufficiency of protective measures, said that all SDS look almost the same with respect to protective (and first-aid) measures regardless of the degree of actual hazard. Similarly, an occupational hygienist described the protective measures in SDSs to be similar for products with different hazards, but explained it with suppliers wanting "to be on the safe side".

The room for interpretation in combination with an abundant use of technical terms, and sometimes in the wrong language, sets 
up barriers for the information flow. Expertise is needed to understand the SDS and instructions therein. However, many smaller companies lack in-house competence as well as resources for hiring consultants, or even the awareness that such competence is needed. Regional safety representatives and consulting OHS professionals report of a low awareness and low understanding of SDSs among smaller companies. Regional safety representatives reported that it is not uncommon to visit employers, especially micro sized, unaware of SDSs.

\subsubsection{The authority perspective}

Also authority informants pointed out that the SDSs were lacking with regards to the RMMs which were described as generally unspecific or vague and sometimes even contradictory. The informants stated to find the RMMs in the SDSs sometimes being excessive and sometimes insufficient. Important was that from the inspection perspective it is difficult to enforce unspecific and vague measures. While SWEA inspects that the RMMs (or equivalently protective measures) in the SDSs are implemented at the workplace, the contents of the SDS, e.g. that different parts of the SDS are consistent and accurate, is inspected by the Swedish Chemicals Agency. The authority informants did not object to this division between SWEA and the Swedish Chemicals Agency, but acknowledge that the evaluation of how the RMMs required by the SDSs perform in practice may fall in between inspection efforts.

\subsection{Teething problems with exposure scenarios}

As a group, OHS professionals were more familiar with exposure scenarios than safety representatives, however also OHS professionals expressed that they lacked knowledge on when exposure scenarios are required and how these are to be communicated along the supply chain. Among safety representatives only a few had heard of extended SDS and exposure scenarios, and not all of these claimed to have seen any yet. This may not only be due to the fact that workplaces have not received any exposure scenarios; in one interview a local safety representative who was unsure whether exposure scenarios had been received also mentioned that there was a centimetre thick SDS in the company's binder of SDSs. Hence, although concepts have been introduced at company and trade union courses and meetings, what the terms actually mean may have eluded those not working with regulatory issues.

Informants familiar with exposure scenarios found them difficult, referring both to the sheer amount of information and the difficulties in interpreting the information. The combination of a large number of different exposure scenarios for substances in the extended safety data sheet and difficulties to ascertain which scenario is relevant for the company operations and use of mixtures makes up a first barrier. A second barrier is the interpretation of recommended operational conditions and RMMs, i.e. understanding how to adhere to the exposure scenarios. This later step was, like the shorter information given in the SDS, described as requiring special expertise and "translation". One occupational hygienist also held the opinion that the RMMs prescribed in some exposure scenarios actually were not the most suitable available. Regional safety representatives expressed concern that the exposure scenarios would not benefit smaller companies, and that the large amount of information perhaps even would discourage them from using the information in the main body of the SDS.

Although sceptical about the current value of exposure scenarios, most informants believed exposure scenarios hold potential as an information pathway about safe working practices. One occupational hygienist stated that exposure scenarios add no value for workplace risk assessment and management, as they only concern single substances and workplaces have mixed exposures.

\subsubsection{The authority perspective}

SWEA informants found that the information flow via the exposure scenarios was hampered by factors lying both at the level of suppliers and downstream users. Suppliers have failed to deliver exposure scenarios, or delivered exposure scenarios of poor quality. With regards to this situation the Swedish Chemicals Agency informant pointed to the unclear regulations on how formulators should forward information from exposure scenarios. As with the main body of the SDS unspecific measure are difficult to enforce for a SWEA inspector. The SWEA inspectors also perceived downstream users that had received exposure scenarios to have been unprepared for applying these in their OHS management. Furthermore, because inspectors cannot know when the exposure scenario was received by the downstream user, they cannot be certain a year has passed and downstream users are obliged to comply with the exposure scenario. Similar to regional safety representatives, authority informants expressed concern for an information overload effect, that too much information in the shape of exposure scenarios may deter companies also from using the main body of the SDS. Again, especially SMEs were seen as disadvantaged.

\subsection{Uncertainty about how DNELs fit in the OEL paradigm}

Early in the interviews informants' knowledge, use and opinion about Swedish OELs were probed, in order to make a comparison to the corresponding factors for DNELs. Not all informants actively used or referred to OELs in their profession or commission, and many reported a decline in use. However, most expressed confidence in Swedish OELs.

The OELs were appreciated because they are a benchmark to evaluate the work environment against, and most importantly a clear indicator if further risk reduction measures have to be taken. As a safety representative put it, showing that an OEL is exceeded leaves no room for discussion about whether to take further action or not.

A variety of opinions on the OELs' level of protection were voiced, ranging from overly protective to suitable and further on to insufficiently protective. Informants that put forward the opinion that OELs are too lenient exemplified with specific OELs, both recently promulgated and older ones. Informants that on the other hand proposed that OELs are set at a low or even too strict level spoke in general terms and did not point out specific examples. The opinions were not divided according to profession or commission. Similar to the safety representatives concerned about authorisation, safety representatives talking about too strict OELs seemed to experience a conflict between the protection of workers' health and the protection of workers' jobs.

Most safety representatives and some OHS professionals had not heard about the DNEL at all. Even knowing about DNELs the understanding of their purpose was poor and, specifically, no connection was drawn between the operational conditions and RMMs described in the exposure scenarios or those in section 8 in the SDS.

Also how DNELs relate to OELs was unclear to the informants. Some stated that DNELs, since they are health-based, are better as an aim for the workplace exposures, but also the opposite opinion was expressed, i.e. that the OELs are better as aims since they take socioeconomic factors into account. There was, however, a general agreement that in case of conflicting values it is the Swedish OEL that takes precedence. For some substances the Swedish OELs are very old (oldest entries in the 2011 list of OELs are from 1974), which was lifted as one cause for having reservations about specific OELs although not as an argument for applying DNELs instead. 


\subsubsection{The authority perspective}

Also SWEA Inspectors find OELs to be needed. As of yet they had little experience of DNELs, but had noted these may be both higher and lower than corresponding OELs. Consequently, the SWEA informants also noted that if a DNEL is higher than the corresponding OEL, adhering to an exposure scenario may not be sufficient for the obligations stemming from OHS legislation. SWEA inspectors perceived it as potentially confusing for companies with two different values for the same substance.

\subsection{Informants' views on ways forward}

REACH implementation is complicated and many informants requested more guidance on how to comply with $\mathrm{REACH}$ requirements. The SWEA Inspectors pointed out a need for more knowledge and competence in chemical safety management and chemicals regulation among SWEA inspectors in general. Workplace hazards are many and diverse, and only a few of SWEAs inspectors focus on chemical risks in the workplace.

There were clear differences in who is considered responsible and/or most suited for improving REACH compliance. Authority informants focused on supply chain actors, mainly through downstream users placing stricter demands on their suppliers with respect to quality and clarity of SDS (readable, comprehensible, clear instructions). Authority informants expressed hopes that the work on guidance documents performed by industrial branch organisations will lead to significant improvements, for instance in the development of more uniform exposure scenarios and also on how to incorporate mixed exposures in them.

OHS professionals and safety representatives instead asked for more guidance from authorities, both SWEA and the Swedish Chemicals Agency. Few were aware of the extensive guidance to downstream users offered by ECHA. Several also stated to have difficulties in identifying who to contact in case of questions about how to comply with REACH, implying the REACH help-desk at the Swedish Chemicals Agency is not well known. When it comes to supply chain efforts some of the OHS professionals put forward a wish that suppliers would identify relevant exposure scenarios and only send these. Only a few seemed to be aware of the option to ask suppliers for clarification about the SDS, and these were OHS professionals in larger companies. Industry initiatives on guidance were generally not referred to, with the exception of OHS professionals that had themselves taken part in such efforts.

\section{Discussion}

In the present study we have interviewed 19 individuals engaged in some aspect of chemicals risk management at the workplace. With the exception of the four authority informants, our informants were recruited by their own initiative in response to our nationwide posting about the study aims in different forums. Our informants are thus not representative of the Swedish situation, rather it is to be expected that the individuals joining our study are those with a specific interest in chemicals risk management and REACH. This was also corroborated by the informants themselves during the interviews. The low number of individuals responding to our interview inquiries may indicate that in comparison to other occupational health issues REACH implementation receives little attention from OHS professionals and safety representatives.

Even though the number of informants is limited in the present study, the different groups included offer a range of perspectives on OHS management among downstream users. Partially this reflects differences in knowledge about regulatory issues, toxicology and occupational hygiene. Safety representatives primarily are employees with limited education in these areas. Our selection was also designed at offering perspectives from a range of different companies. Perspectives from SMEs, and especially micro sized and small enterprises, are offered by OHS professionals that are consultants, labour inspectors and regional safety representatives. These individuals have experience from a large number of SMEs, which increases the generalizability of their accounts.

We found that REACH implementation was not perceived as having had any major impact on downstream users' occupational risk management. This is likely connected to the finding that many companies, especially SMEs, are uncertain about, or even unaware of, their REACH obligations. However, as had been expected REACH implementation has increased availability of, and facilitated access to, information about chemical risks, albeit not necessarily about chemicals risk management. In the group targeted by the present study, supplier-user communication had not been affected by REACH implementation. That only a few informants reported about communication up the supply chain could be because small end users are not aware of the possibility, or do not believe it worthwhile, to ask suppliers for more specific guidance on chemicals risk management.

Our informants generally seemed to be of the view that REACH obligations were not pushing for substitution. Nevertheless, closer probing on specific parts of REACH procedures showed that REACH does have some impact on substitution, either by requiring it for certain substances as through the authorisation procedure or facilitating identification of relevant substances to substitute through increased information on hazards. However, contrary to the expectations by for instance Cohen's (2011) informants the candidate list was not perceived as a substitution driver by our informants.

Our informants described SDSs as improved, mainly due to more information about hazards being available (or disclosed) and systematic naming of substances. However, these improvements do not meet all issues that previous research on SDSs has identified. Lacking quality of information from suppliers and limited capacity of SMEs to use it are long-known issues hampering effective risk management. Critical aspects, such as unclear or insufficient information about RMMs, seem still to be unresolved. The habit of describing generic RMMs in the SDS is a contributing factor to a major part of the complaints about SDSs, which connect to previous findings of previous studies of SDSs (e.g. Nicol et al., 2008). The findings of the present study show that the issues with SDSs and supply chain communication are far from resolved by the current state of implementation of REACH.

As expected some of our informants' employers had received exposure scenarios for single substances but not for mixtures. Even though the first registration deadline was several years past, not all informants knew about exposure scenarios or had seen any. Part of the explanation is that our informants mainly were end users of chemical products and mostly use mixtures rather than singe substances. The requirements regarding chemical safety assessments and the compilation of exposure scenarios only apply to single substances. REACH requirements are unclear on how information from an exposure scenario is to be distributed further down the supply chain as single substances are incorporated into mixtures and products, in practice this seems to have resulted in exposure scenarios stopping at the formulator level of the supply chain. Exposure scenarios may be derived for mixtures, but this would be performed on a voluntary basis by the concerned suppliers.

Hence, there are two major limitations to the concept of exposure scenarios. First they are not reaching the whole supply chain. Second, they are most likely to not be available for mixtures. Should exposure scenarios be supplied for single substances included in a product, the information may quickly reach overwhelming amounts. Around 100 chemical products is not an 
uncommon number, even for small downstream users. For each product containing one or several substances with exposure scenarios the downstream user would have to go through and understand several (these may also be in the 100s) exposure scenarios. The outcome for each substance would then have to be combined in order to identify correct uses for the downstream user's own operations. Hence, it is questionable if the introduction of exposure scenarios should be expected to play a major role for downstream users' OHS management. However, to date most informants having experience of exposure scenarios attributed the dubious value of exposure scenarios for risk management to poor quality rather than poor coverage.

Except authority informants, none of our informants connected DNELs to the building of exposure scenarios. Many were even not aware of the concept of DNELs. Informants who were familiar with DNELs tended to either disregard DNELs completely in their practice or at most view them as something to compare OELs with. Assuming the many difficulties in ascertaining how to comply with exposure scenarios are resolved, issues with lack of awareness and understanding of DNELs may arise in case of discrepancies between DNELs and OELs. Almost 20\% of currently available DNELs for substances with a Swedish OEL exceed that OEL by at least a factor of two (Schenk et al., 2015). For German and Finnish OELs the picture is the same (Nies et al., 2013; Tynkkynen et al., 2015). For substances with DNELs higher than corresponding OELs, exposure scenarios may be insufficient under national OHS legislation (regardless of which limit is more 'toxicologically correct').

Concerns about the quality of the submitted information including the DNELs have been raised (e.g. European Commission, 2013). Currently there is no REACH procedure under which authorities may enforce an update of a poorly derived or an outdated DNEL. As downstream users stand to lose from both too restrictive (i.e. likely to bring about unnecessary RMM costs) and too allowing (i.e. not sufficiently protective of employees' health) supply chain pressure could be a mechanism for scrutiny of DNELs. However, the lack of awareness of DNELs existence and/ or function means there is no basis to assume that downstream users will have any incentive to scrutinize DNELs from a quality perspective. Despite there being some concerns about the quality of DNELs, the large effort in establishing a first exposure benchmark for the many substances lacking OELs is a valuable outcome of REACH. However, another implication of the low awareness of DNELs is that this resource most likely is underutilized as a source of risk information.

The introduction of a new regulation and its implementation among duty holders can be seen as a continuum from awareness to understanding to action (cf. Legg et al., 2015). As REACH obligations in many cases are separated by tonnage levels (a rough approximate for company size) and role in the supply chain we would expect different companies to fall into different parts of this continuum. Experience from the implementation of the OHS legislation to date (Walters, 2006; Sørensen et al., 2007; Olsen et al., 2010; Lißner and Zayzon, 2011) further leads us to expect that especially SMEs will lag behind in this continuum. It is thus hardly surprising that our informants report on lacking awareness and understanding among downstream SMEs.

Lacking awareness of one's obligation as a downstream user obviously hampers the realisation of many of the benefits REACH is expected to bring to OHS management. Improvements in risk assessments and RMMs depend on communication up the supply chain to be realised. Also implementation of exposure scenarios depends on downstream users taking action. Improvements such as that of substance identification and hazard information in the SDS does not necessarily require REACH awareness, however, our results corroborate the picture of many SMEs being unaware of not only REACH but also OHS legislations. Hence, stakeholders need to engage in activities raising awareness and understanding as well as promoting action.

The supply chain is central to risk management under REACH. As has also been pointed out by Walters (2008) the fact that many actors providing assistance for SMEs in understanding and acting on information from suppliers are not part of the supply chain has implications for the implementation of REACH. In the present study we saw a distinct difference between informants, where informants from authorities were emphasising the responsibilities of supply chain actors. Our other informants, with experience from SMEs as well as larger enterprises, on the other hand requested more assistance from regulatory agencies rather than suppliers or industry organisations. These differences to some degree probably are due to differences in awareness of REACH obligations and initiatives to provide REACH guidance. Our findings with respect to awareness and understanding of suppliers' information also confirm that SMEs still need more, or different to currently available, support from actors outside the supply chain. It is however not obvious what kind of measures that can solve this problem. It is clear that different actors frame the issues differently, meaning that both problem formulations and solutions need to be discussed between different groups of stakeholders. Implementation of $\mathrm{REACH}$ is a complex problem which requires complex actions.

Safety representatives, most importantly regional, may serve as a valuable initial information source for employers about REACH obligations that affect OHS management (see also Musu, 2010). Regional safety representatives visit small and micro sized companies, a target group difficult to reach. Although there is limited evidence of the direct effects on OHS, such face-to-face communication has been proposed as an important factor influence on the behaviour of employers and workers at SMEs (Walters, 2008). Safety representatives are generally appointed by a trade union, and trade union membership is comparably high in Sweden compared to most other EU countries although it is, like in other countries, declining (Frick, 2013). Given the role of the regional safety representatives in Sweden educational efforts by trade unions could thus promote the benefits that REACH has to offer OHS management. However, due to trends in trade union membership this is likely not transferable to most other EU countries.

Inspections from enforcing authorities may be one means to target lack of awareness but also the issues with poor quality e.g. unclear information on proper uses and RMMs in SDSs and exposure scenarios. In Sweden, the Swedish Chemicals Agency is responsible for inspecting the contents of SDSs, on the other hand it is the SWEA inspectors that specialize on chemical risks that hold the most relevant knowledge on how SDSs (fail to) assist OHS management. Close collaboration between the Swedish Chemicals Agency and SWEA is needed in order to efficiently identify flaws in SDSs and exposure scenarios regarding RMMs. It will also be of major importance that the chemical risk management competence of the SWEA inspectorate is maintained, so that SWEA inspection activities may continue to inform and correct inspected companies as well as inform the Swedish Chemicals Agency.

\subsection{Conclusions}

The results of the present study outline a picture where REACH implementation has not had major impacts on downstream users' OHS management, but the impact it has had has been positive. REACH has had some impact on substitution, either by requiring it for certain substances as through the authorisation procedure or facilitating the identification of relevant substances to substitute as more information on hazards has become available, e.g. through the SDSs. Another appreciated improvement of the SDSs is clear substance identification. However, with regards to identifying 
how to safely use a substance or product neither the SDSs nor the attached exposure scenarios were perceived as sufficient. However, our informants expected that with additional time REACH will bring more benefits for occupational health and safety. The obstacles to REACH implementation are the same as has been obstacles to implementation of OHS legislation; lack of awareness, understanding and/or incentives to take action. Especially SME's with their limited resources are lagging behind. To reach the full potential of REACH more work has to be put into motivating and supporting downstream users to fulfil their REACH obligations.

\section{Funding}

The Swedish Research Council for Health, Working Life and Welfare (Forte). The funding agency had no part in study design, performance or writing of this manuscript.

\section{Acknowledgements}

The authors wish to thank the informants whose generous contributions made the study possible and the organisations (FTF, SYMF, LO and IF Metall) that provided contacts with their members.

\section{References}

Cohen, A.K., 2011. The implementation of REACH: initial perspectives from government, industry, and civil society. Int. J. Occup. Environ. Health 17, 57-62.

Ding, Q., Schenk, L., Malkiewicz, K., Hansson, S.O., 2011. Occupational exposure limits in Europe and Asia - continued divergence or global harmonization? Regul. Toxicol. Pharmacol. 61, 296-309.

EU, 1989. Council Directive 89/391/EEC of 12 June 1989 on the Introduction of Measures to Encourage Improvements in the Safety and Health of Workers at Work. OJ 183/1.

EU, 1998. Council Directive 98/24/EC of 7 April 1998 on the Protection of the Health and Safety of Workers from the Risks Related to Chemical Agents at Work (Fourteenth Individual Directive Within the Meaning of Article 16(1) of Directive 89/391/EEC), OJ L 131/11.

EU, 2006. Registration, Evaluation, Authorisation and Restriction of Chemicals (REACH). Regulation (EC) No. 1907/2006 of the European Parliament and of the Council. OJ L 396/17.

EU, 2008. Regulation (EC) No 1272/2008 of the European Parliament and of the Council of 16 December 2008 on Classification, Labelling and Packaging of Substances and Mixtures, Amending and Repealing Directives 67/548/EEC and 1999/45/EC, and Amending Regulation (EC) No 1907/2006. OJ L 353/1.

ECHA - European Chemicals Agency, 2012. Characterisation of dose [concentration]-response for human health (Chapter R.8), <http://echa.europa. eu/documents/10162/13632/information_requirements_r8_en.pdf $>$.

ECHA - European Chemicals Agency, 2014. Guidance on the Compilation of Safety Data Sheets. Version 2.1 February 2014.

European Commission, 2013. Report from the Commission to the European Parliament, the Council, the European Economic and Social Committee and the Committee of the Regions in Accordance with Article 117(4) of REACH and Article 46(2) of CLP, and a Review in Line With Articles 75(2), 138(2), 138(3) and 138(6) of REACH. Brussels: European Commission.

Frick, K., 2013. Resilience within a weaker work environment system - the position and influence of Swedish safety representatives. In: Walters, D., Nichols, T. (Eds.), Safety or Profit? International Studies in Governance, Change and the Work Environment. Baywood Publishing Company, New York, pp. 51-70.

Hammerschmidt, T., Marx, R., 2014. REACH and occupational health and safety. Environ. Sci. Eur. 26, 6.

Legg, S.J., Olsen, K.B., Laird, I.S., Hasle, P., 2015. Managing safety in small and medium enterprises. Saf. Sci. 71, 189-196.
Lißner, L., Zayzon, R., 2011. Is the European Directive 98/24/EC on Chemical Agents effective? Evaluation of its practical implementation at workplaces. Gefahrst. Reinhalt. L. 71, 247-254.

Musu, T., 2004. REACHing the workplace. How workers stand to benefit from the new European policy on chemical agents. European Trade Union Technical Bureau for Health and Safety, <http://www.etui.org/content/download/2100/ 23315/file/Reaching_workplace_EN.pdf $>$.

Musu, T., 2010. REACH: an opportunity for trade unions. Putting Knowledge to Work in the Workplace. ETUI, Brussels.

Nicol, A.-M., Hurell, A.C., Wahyuni, D., McDowall, W., Chu, W., 2008. Accuracy, comprehensibility, and use of material safety data sheets: a review. Am. J. Ind Med. 51, 861-876.

Nies, E., Musanke, U., Püringer, J., Rühl, R., Arnine, M., 2013. DNELs for workplaces observations from an inspection of the DGUV DNEL list. Gefahrstoffe Reinhaltund der Luft 73 (11/12), 455-462.

Niskanen, T., Louhelainen, K., Hirvonen, M.L., 2014. Results of the Finnish national survey investigating safety management collaboration and work environment in the chemical industry. Saf. Sci. 70, 233-245.

Olsen, K., Harris, L.-A., Laird, I., Legg, S., Perry, M., Hasle, P., 2010. Differential intervention strategies to improve the management of hazardous chemicals in small enterprises. Policy Practice Health Saf. 8, 57-76.

Oltmanns, J., Bunke, D., Jenseit, W., Heidorn, C., 2014. The impact of REACH on classification for human health hazards. Regul. Toxicol. Pharmacol. 70, 474481.

Patton, M.Q., 2002. Qualitative Research and Evaluation Methods. SAGE, London.

Pelkmans, J., Schrefer, L., Gubbels, I., 2013. The consequences of REACH for SMEs. Briefing Note prepared for the European Parliament, Committee on Industry Research and Energy, PE 507.486, October, <http://www.europarl.europa.eu/ studies>.

Pickvance, S., Karnon, J., Peters, J., El-Arifi, K., 2005. Further assessment of the impact of REACH on occupational health with focus on skin and respiratory diseases. ETUI-REHS.

RPA - Risk \& Policy Analysis, 2003. Assessment of the Impact of the New Chemicals Policy on Occupational Health. Final Report March 2003, Project J414/Occup. London.

RPA - Risk \& Policy Analysis, 2012. Assessment of the Health and Environmental Benefits of REACH. Part B - Assessment of Benefits. Final Report April 2012, Tender no ENV.D3./SER/2011/0027r. London.

Schenk, L., Johanson, G., 2011. A quantitative comparison of the safety margins in the European indicative occupational exposure limits and the derived no-effect levels for workers under REACH. Toxicol. Sci. 121, 408-416.

Schenk, L., Palmen, N.G.M., 2013. Throwing the baby out with the bath water? Occupational hygienists' views on the revised Dutch system for Occupational Exposure Limits. Ann. Occup. Hyg. 57, 581-592.

Schenk, L., Deng, U., Johanson, G., 2015. Derived No-Effect Levels (DNELs) under the European chemicals regulation REACH - an analysis of long-term inhalation worker-DNELs presented by industry. Ann. Occup. Hyg. 59, 416-438.

Scruggs, C.E., Ortolano, L., Wilson, M.P., Schwarzman, M.R., 2015. Effect of company size on potential for REACH compliance and selection of safer chemicals. Environ. Sci. Policy 45, 79-91.

Sørensen, O.H., Hasle, P., Bach, E., 2007. Working in small enterprises - Is there a special risk? Saf. Sci. 45, 1044-1059.

Suleiman, A.M., Svendsen, K.V.H., 2014. Are safety data sheets for cleaning products used in Norway a factor contributing to the risk of workers exposure to chemicals? Int. J. Occup. Med. Environ. Health 27, 840-853.

SWEA - Swedish Work Environment Authority, 2001. Systematiskt Arbetsmiljöarbete [Systematic Work Environment Management], AFS 2001:1. Swedish Work Environment Authority, Solna.

SWEA - Swedish Work Environment Authority (2011a). Kemiska Arbetsmiljörisker [Chemical Risks at the Workplace]. AFS 2011:19. Elanders, Stockholm.

SWEA - Swedish Work Environment Authority (2011b). Hygieniska gränsvärden AFS 2011:18. Elanders, Stockholm.

Swedish Parliament, 1977. Swedish Work Environment Act.

Tynkkynen, S., Santonen, T., Stockmann-Juvala, H., 2015. A comparison of REACHderived no-effect levels for workers with EU indicative occupational exposure limit values and national limit values in Finland. Ann. Occup. Hyg. 59, 401-415.

Walters, D., 2006. The efficacy of strategies for chemical risk management in small enterprises in Europe: evidence for success? Policy Practice Health Saf. 4, 81116.

Walters, D., 2008. Within REACH?: Managing Chemical Risks in Small Enterprises. Baywood Publishing, Amityville, NY. 